\title{
Селиверстов А.А. \\ Проект и реализация малой архитектурной формы для детского сада города Петрозаводска
}

ФГБОУ ВО «Петрозаводский государственный университет»

(Россия, Петрозаводск)

doi: 10.18411/trnio-10-2021-65

\section{Аннотация}

В статье сообщается об участии студентов Института лесных, горных и строительных наук в проектной деятельности. Разрабатываются проекты для объектов ландшафтной архитектуры, которые способствуют развитию универсальных и профессиональных компетенций у студентов.

технологии.

Ключевые слова: проектная деятельность, объект ландшафтной архитектуры,

\section{Abstract}

The article reports on the work of students of the Institute of Forestry, Mining and Construction Sciences in project activities. Is developing projects for landscape architecture objects which contribute to the development of universal and professional competencies in students.

Keywords: project activities, landscape architecture object, technology's.

Обучающиеся Института лесных, горных и строительных наук (ИЛГСН) по направлению подготовка бакалавриата «Ландшафтная архитектура» (профиль «Ландшафтное проектирование и дизайн») по дисциплине «Компьютерное проектирование» принимают активное участие в проектной деятельности по разработке отдельных элементов проекта для объекта ландшафтной архитектуры (парков, дворовых территорий, школьных участков) [1], [3], [4].

Такая организация в обучении способствует развитию специфических умений и навыков проектирования у студентов. Например, обучающимся предоставляется возможность самостоятельного выбора оптимальных методов и средств разработки отдельных элементов и фрагментов объекта ландшафтной архитектуры (в т.ч., с помощью компьютерных программ «AutoCAD», «Autodesk 3DS Max», «SketchUp» или др.). Для работы определяются необходимые материалы и технологии при строительстве объектов ландшафтной архитектуры и садово-паркового строительства [2]. При этом преподаватель выступает в качестве руководителя в решении конкретных задач проекта. Одним из примеров реализованной на практике работы служит реализация малой архитектурной формы для скейт-парка на стадионе «Юность» в городе Петрозаводск, осень 2020 года (рисунок 1) [4].

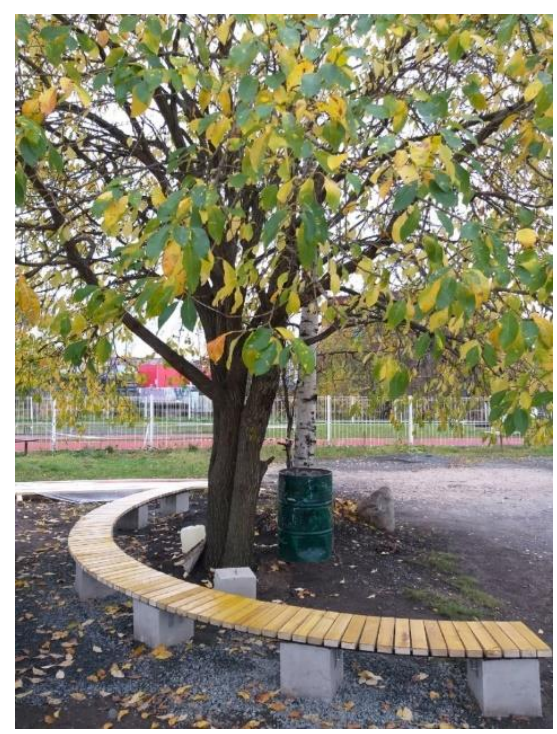

Рисунок 1. Полукруглая скамейка 
Одна из проектных работ студентов была посвящена реализации малых архитектурных форм для детского сада города Петрозаводска весной 2021 года (рисунок 2).
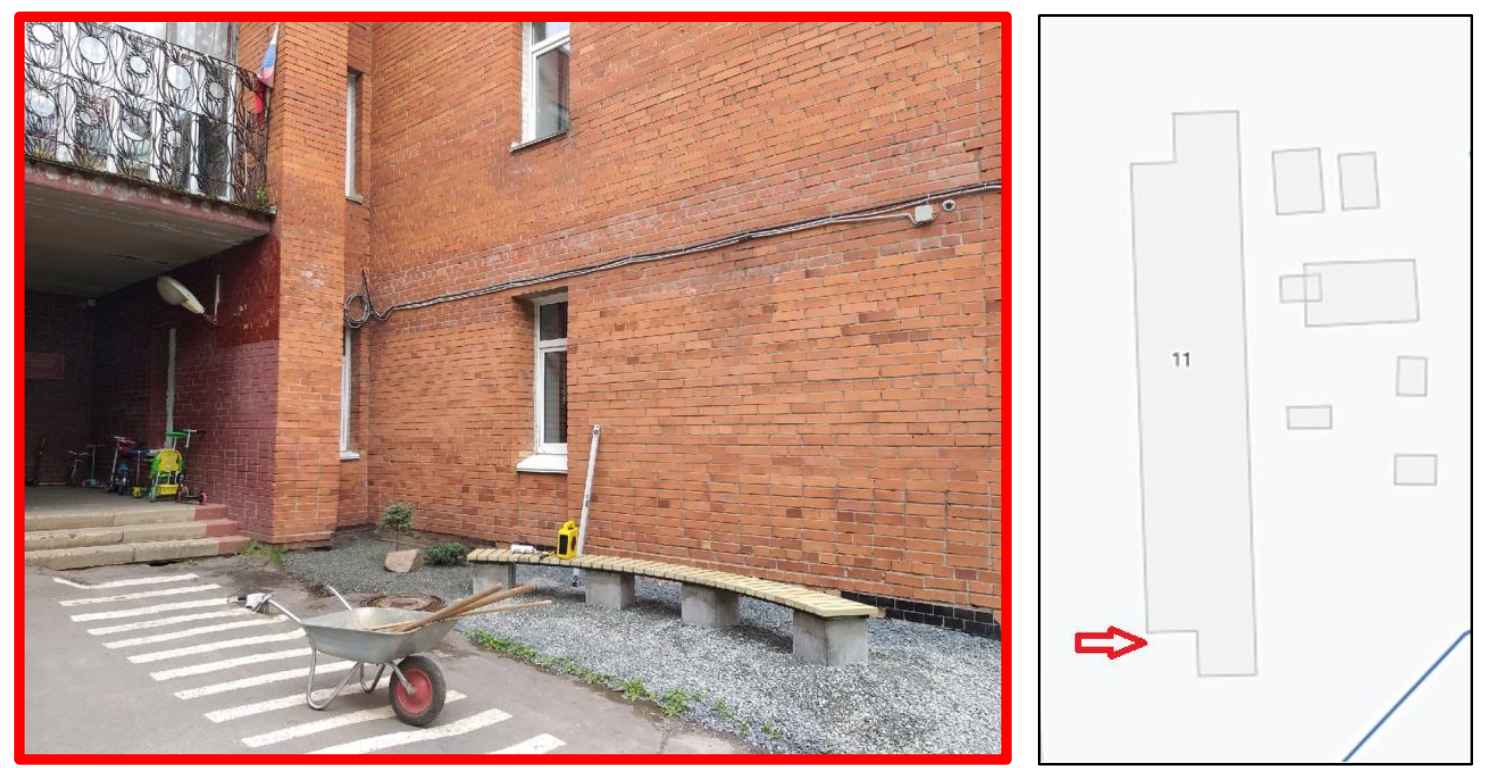

Рисунок 2. Размещение скамейки (юго-западная солнечная зона у входа в здание)

Для размещения малых архитектурных форм проводилось необходимое обследование элементов ландшафта. Было запланировано изучение ассортимента цветочных растений с последующим переносом цветника (рисунок 3 ).

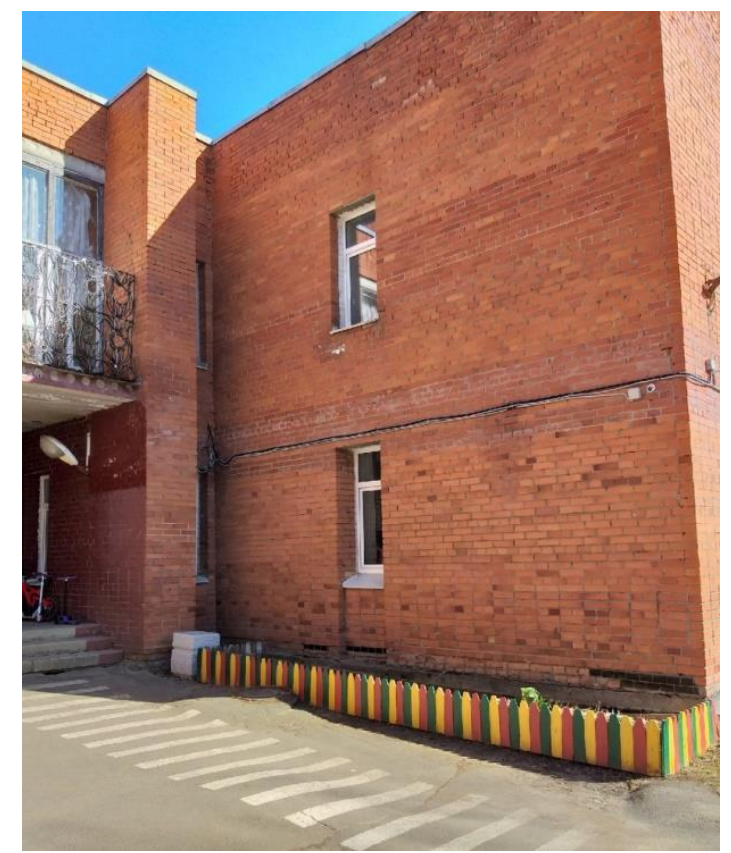

Рисунок 3. Цветник

Разработка трехмерной модели скамейки выполнялась в среде программы моделирования «Autodesk 3DS Maх» с учетом последующего изготовления технологичной модульной конструкции. Затем в процессе изготовления скамейки студенты ознакомились со слесарными, сварочными, плотницкими и покрасочными работами [4].

Перед установкой скамейки студентами выполнялись планировочные и земляные работы, включающие подготовку основания для размещения скамейки и посадку растений, а именно, туя западная «Thuja occidentalis Little Gem» и можжевельник казацкий «Јuniperus sabina». 
На конференции обучающихся и молодых ученых ИЛГСН на секции "Ландшафтная архитектура и лесное дело", студенты представили результаты решения конкретной задачи проекта.

Таким образом, все это способствует формированию у обучающихся универсальных и профессиональных компетенций по направлению обучения.

$$
* * *
$$

1. Ольхин Ю.В. Малые архитектурные формы в композиции ландшафтного дизайна, озеленения и благоустройства общественных пространств [Электронный ресурс] / Ю.В. Ольхин, А.А. Селиверстов // "Тенденции развития науки и образования". - Самара, 2018. - №42. Часть 4. - С.88-91.

2. Ольхин Ю.В. Мой красивый двор. Ландшафтно-планировочная организация территорий жилой застройки [Электронный ресурс] / Ю.В. Ольхин, О.И. Гаврилова. Петрозаводск : ШКИБЦ, 2017. - Режим доступа: http://skbic.ru/file.php/id/f5687-fileoriginal.pdf/name/Ольхин_Ландшафтное\%20обустройство\%20развороты.pdf

3. Селиверстов А.А. Опыт создания объектов малой архитектурной формы на территории ПетрГУ . 2-я Международная научная конференция перспективных разработок молодых ученых «Наука молодых будущее России». Сборник научных статей 13-14 декабря 2017 года / А.А. Селиверстов, Д.В. Рожин // «Университетская книга». - Юго-Западный государственный университет (ЮЗГУ), г. Курск, 2017. - Т.4. C.180-183.

4. Селиверстов А.А. Проект и реализация малой архитектурной формы для Скейт-парка города Петрозаводска / А.А. Селиверстов, С.Н. Перский, И.В. Симонова // Повышение эффективности лесного комплекса : материалы Седьмой Всероссийской национальной научно-практической конференции с международным участием . - Петрозаводск, 2021. - С.170-171. 